\title{
Evaluation of Some Physico-chemical and Antioxidant Characteristics of Commercial Honey Samples Originated from Different Regions of Turkey
}

\section{Mehmet Gültekin Bilgin', Ayșe Güneş Bayır²*, Bilge Özkan³, Zeynep Özman ${ }^{4}$, Fatmanur Babalı Balıbey ${ }^{4}$, Feyzanur Turgay ${ }^{5}$, İrem Karakaş ${ }^{5}$, Nesrin Köse ${ }^{5}$, Tülay Sevinç ${ }^{5}$, Tuğbanur Selçuk ${ }^{5}$ and Nezire Öztürk ${ }^{5}$}

1Assistant Professor, Bezmialem Vakif University, Faculty of Health Sciences,

Department of Nutrition and Dietetics, Eyüpsultan, Istanbul, Turkey

2Associate Professor, Bezmialem Vakif University, Faculty of Health Sciences,

Department of Nutrition and Dietetics, Eyüpsultan, Istanbul, Turkey

3Food Technician, Bezmialem Vakif University, Faculty of Health Sciences,

Department of Nutrition and Dietetics, Eyüpsultan, Istanbul, Turkey

4Research Assistant, Bezmialem Vakif University, Faculty of Medicine, Department

of Medical Biochemistry, Fatih, Istanbul, Turkey

5Dietitian, Bezmialem Vakif University, Faculty of Health Sciences, Department of

Nutrition and Dietetics, Eyüpsultan, Istanbul, Turkey

*Corresponding Author: Ayşe Güneş-Bayır, Associate Professor, Bezmialem Vakif

University, Faculty of Health Sciences, Department of Nutrition and Dietetics,

Eyüpsultan, Istanbul, Turkey.
Received: November 23, 2021

Published: December 15, 2021

(C) All rights are reserved by Bilgin., et al.

\begin{abstract}
Recently encountered pandemic SARS-CoV-2 infection is a serious concern in the worldwide. In order to prevent this disease and to avoid the side effects of the drugs used during the treatment of SARS-CoV-2 infection, humans turned to the consumption of natural foods including bee products. Honey is an important bee product rich in antioxidants, but should be suitable for consumption in terms of food control and safety. Therefore, the present study was undertaken to determine the physico-chemical and the antioxidant characteristics of commercial honey samples originated from 7 different regions of Turkey as well as, to interpret the results with the Turkish Food Codex and European Commission Regulation. Total antioxidant capacity including polyphenols was highest in 100g honey from Agean Region (100 mmol Ascorbic acid Eq and mg Gallic acid Eq, respectively) whereas flavonoid content was the highest in honey from Mediterranean Region. It was found that 19 honey samples (63.3\%) were suitable for the Codex Honey Communiqué in terms of sucrose, invert sugar (glucose and fructose), moisture content, number of diastases, hydroxymethylfurfural (HMF), commercial glucose and pollen analyzes. The honey samples originated from seven different regions of Turkey showed more than half good quality. Their quality depends on various factors such as floral source, geographical origin, harvest seasons, packaging, processing conditions, and storage conditions. Therefore, the consumer's awareness and the education of beekeepers can improve the production and sales for good quality honey.
\end{abstract}

Keywords: Honey; Antioxidant Capacity; Polyphenols; Flavonoids; Hydroxymethylfurfural; Diastase

\section{Introduction}

Honey has a potential as natural antioxidant source for preventing several acute and chronic diseases which include diseases related to inflammation, diabetes, cardiovascular, and cancer [1]. Re- cently, an in silico research revelad that honey may be able to bind SARS-CoV-2 protease, and so inhibit SARS-CoV-2 proteases and some compounds of honey [2]. Also, honey shows anti-thrombotic activity due to the inhibiton of PAF $[3,4]$. Therefore, honey may 
useful food against the SARS-CoV-2 infection. On the other hand, increasing tendency of healthy nutrition leads to the consumption of natural foods. Honey has an important role in health protection and also the growth of healthy individuals. Especially in 2020, the total 5974 tonne honey were exported from Turkey to 52 countries including Germany, USA, Saudi Arabia, Kuwait and Oman [5]. During this period, honey exports increased by approximately 8 percent compared to 2019.

According to the Turkish Food Codex, honey is defined as a natural product of plant nectars, secretions of plants on the living parts of plants, after being collected by honey bee combining with unique substances, reducing water content and storing in honeycomb [6]. Besides sugar as main component of honey, it consist of enzymes, amino acids, organic acids, carotenoids, vitamins, minerals, aromatic and antioxidant substances [7]. Plants used by bees vary according to region and climate conditions which affect the chemical composition of honey [8]. Color, aroma, and taste of honey mainly depends on the flower, the geographical area to which it is produced, the climate and the type of honey bee that makes the honey, as well as weather conditions, processing time, fraud, packaging and storage time [7]. There are several parameters that determine the qualitative and nutritional properties of honey. Geographic region, climatic conditions and vegetation cover of honey bees are the main factors affecting the main character of honey. In order to compare the results of another studies and to determine the compatibility of honey samples with the Turkish Food Codex [6] and European Comission Regulation [9], the acidity, invert sugar, sucrose, moisture, hydroxymethylfurfural (HMF), and viscosity were investigated. Analyzes of pollen and antioxidant capacity including polyphenols and flavonoids were also carried out to determine the nutritional value of honey samples.

The most pratical way to distinguish fresh honey from honeys that have been overheated or stored for a long time is to measure diastase and HMF activities [10]. HMF and diastase are expected for international quality standarts of honey [11-13]. HMF is a product produced by the breakdown of sugar in honey subjected to heat treatment [14]. HMF is almost never found in fresh honey. It occured only during acid-catalyzed dehydration of hexoses such as fructose or glucose. Additionally, it can be affected from storage conditions and source of flowers [11-13]. The degree and duration of the heat treatment, storage conditions (such as light exposure) and the use of metal containers in storage can cause of the increase in the amount of HMF in the honey [15-17]. Diastase is a kind of enzyme that is inactivated by heat [14]. It is the amount of starch that the amylase enzymes disintegrate within 1 hour at $38-40^{\circ} \mathrm{C}$ up to the predetermined end point in 100 grams of honey. Commercial glucose is the biggest factor that causes deception in honey that has a market and plays an important role in determining the quality of honey. The acidity in honey is related to factors such as flower sources, amount of minerals, harvest time and the amount of glyconic acid resulting from the enzymatic effect on glucose [8,18-21]. The viscosity is the tendency of a liquid to have internal friction or resistance to flow. Viscosity has a great potential for the food industry because the test procedure is simple, easy to apply and fast. As expected, the viscosity decreases significantly with an increasing temperature for each sample [21].

Pollen analysis of honeys gives information about the vegetation in the region where the honeybee is growing [22]. Pollen also affects the quality of honey and helps to determine whether it is honey or not. Turkey has a rich structure due to bee breeding, ballistic geography, climate, and vegetation. Beekeeping is an important activity that continued for thousands of years in Turkey. Therefore, there are many varieties of bee products including honey in the country, whereas consumers prefer honey more than other products [23]. Additionally, most of the consumers prefer to buy honey from producers and markets. Therefore, the present study was conducted to investigate the quality of 30 honey samples obtained from various 7 geographical regions of Turkey. Briefly, the purpose of this study was to determine the identity and the quality parameters of honey compounds by examining them in terms of their physico-chemical and antioxidant properties.

\section{Materials and Methods}

Chemicals and reagents

Carrez I (0.25 M potasyum ferrosiyanür, Merck), Carrez II (1 M zinc acetate, Merck), Fehling A [(69.28 + 0.05 g copper (II) sulphate pentahydrate $\left.\left(\mathrm{CuSO}_{4} .5 \mathrm{H}_{2} \mathrm{O}\right) \mathrm{Merck}\right] / 1000 \mathrm{~mL}$ distilled water, Fehling $\mathrm{B}[(346+0.1 \mathrm{~g}$ sodium potassium tartrate tetrahydrate $\left(\mathrm{Ca}_{4} \mathrm{H}_{4} \mathrm{O}_{6} \mathrm{NaK} .4 \mathrm{H}_{2} \mathrm{O}\right)$ (Merck) $+100+0.1 \mathrm{~g}$ sodium hydroxide $(\mathrm{NaOH}) \mathrm{Merck}] / 1000 \mathrm{~mL}$, methylene blue $(0.2 \%)$ Merck, hydrochloric acid $(\mathrm{HCl}=1.19 \mathrm{~g} / \mathrm{mL})$ Merck, sodium hydroxide $(5 \mathrm{M} \mathrm{NaOH})$ Merck, phenolphthalein (1\% ethyl alcohol) Merck, formic acid (Merck), ammonium oxalate (Merck), ethyl alcohol (Isolab Chemicals), barbituric acid (Merck), iodine solution (Merck), starch 
(Merck), buffer mixture of phosphate/citrate (citric acid monohydrate $\left[\left(\mathrm{C}_{6} \mathrm{H}_{8} \mathrm{O}_{7} \cdot \mathrm{H}_{2} \mathrm{O}\right) /\right.$ disodium hydrogen phosphate dihydrate $\left(\mathrm{Na}_{2} \mathrm{HPO}_{4} \cdot 2 \mathrm{H}_{2} \mathrm{O}\right)$ (Merck), and p-toluidine (Merck). Acetic acid, aluminum nitrate $\left(\mathrm{Al}\left(\mathrm{NO}_{3}\right)_{3}\right)$, gallic acid, potassium acetate, sodium carbonate $\left(\mathrm{Na}_{2} \mathrm{CO}_{3}\right)$, quercetin, ascorbic acid, and 2,2'-azinobis-(3-ethylbenzothiazoline-6-sulfonate) (ABTS) were purchased from Sigma-Aldrich (Darmstadt, Germany). Ethylene glycol, hydrogen peroxide, dimethyl sulfoxide (DMSO), and ethanol were purchased from Merck (Darmstadt, Germany).

\section{Honey samples}

Thirty honey samples obtained from seven different geographical regions of Turkey were collected (Figure 1). The samples were stored in a dry and a dark place at room temperature. In order to determine antioxidant capacity, representing 7 geographical regions seven different honey samples of them were subjected to analyze. All samples were stored at $4^{\circ} \mathrm{C}$ in the dark until analyses and just before use for the experiments honey samples (10 g) were heated in an ultrasonic water bath (Memmert, Germany) for $15 \mathrm{~min}$ then, dissolved in distilled water.

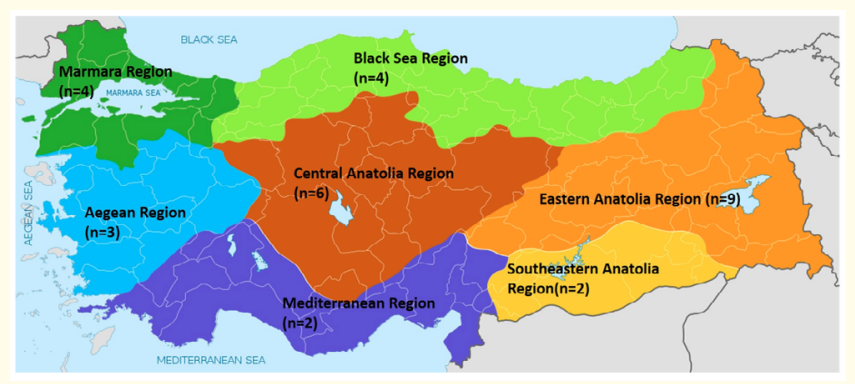

Figure 1: Honey samples $(n=30)$ were obtained from 7 different geographical regions of Turkey.

Physico-chemico analyzes of honey samples

Invert sugar analysis

During the study, the determination of invert sugar in honey was made by adding $1 \mathrm{~mL}$ of honey sample to $40 \mathrm{~mL}$ water to form a homogeneous mixture. Five $\mathrm{mL}$ of Carrez I and $5 \mathrm{~mL}$ of Carrez II were added to this solution that was completed to $100 \mathrm{~mL}$ with distilled water and then filtered. A mixture of $5 \mathrm{~mL}$ Fehling A and $5 \mathrm{~mL}$ Fehling $\mathrm{B}$ was heated on the light flame and 2 drops of met- hylene blue were added to the boiling temperature. Ten $\mathrm{mL}$ of the previously filtered solution was titrated on the burner flame. The value obtained was used to calculate the percentage of invert sugar by recording $[24,25]$.

\section{Saccharose analysis}

One g of honey is taken and dissolved in the beaker with $40 \mathrm{~mL}$ of water. Then, $1 \mathrm{~mL}$ of $\mathrm{HCl}$ was added to the volumetric flask and placed in a water bath (up) for 15 minutes. After cooling, $2 \mathrm{~mL}$ of phenolphthalein was added, and then the volumetric flask was titrated with $\mathrm{NaOH}$. Five $\mathrm{mL}$ of Carrez I, $5 \mathrm{~mL}$ of Carrez II and some water were added to the volumetric flask. This mixture was filtered to the erlene and then burned to the flame. A few drops of methylene blue were dripped and titrated by boiling. For the titration, $5 \mathrm{~mL}$ Fehling A and $5 \mathrm{~mL}$ Fehling B mixture were used [24,25].

\section{Determination of acidity}

Five grams of honey sample were weighed from the samples and diluted with $75 \mathrm{~mL}$ of distilled water. Erlen was throughly mixed and dissolved. A few drops of phenolphthalein were added to the erlen. Titration was carried out with $0.1 \mathrm{~N} \mathrm{NaOH}$ solution until light pink color obtained. The resulting color was stable for 15 seconds. The amount of $\mathrm{NaOH}$ spent in titration was recorded. Thus, the sum of the acids present in $1 \mathrm{~kg}$ of honey is calculated as the result of the number of milliequencies in formic acid [24,25].

\section{Determination of commercial glucose}

Five grams of honey was mixed with $10 \mathrm{~mL}$ of water. After adding a few drops of a $10 \%$ solution of ammonium oxalate to the honey samples. The mixture was put on the burner flame. After adding some activated carbon to the boiling mixture, it was taken from the burner flame and filtered into the tubes. One $\mathrm{mL}$ of $\mathrm{HCl}$ and $10 \mathrm{~mL}$ of ethyl alcohol was added to the filtrate. If the sample contains commercial glucose, turbidity in the solution occurs. If there is no commercial glucose, the solution should be clear $[25,26]$.

\section{Determination of HMF}

A spectrophotometric method was used to determine the amount of HMF. According to this method, 10 grams of honey were dissolved in $20 \mathrm{~mL}$ water and transferred to a 50 volumetric flask. 2 $\mathrm{mL}$ of the solution and $5 \mathrm{~mL}$ of $\mathrm{p}$-toluidine solution were put in two different test tubes; to one tube was added $1 \mathrm{~mL}$ of distilled water (reference solution); to the second, $1 \mathrm{~mL}$ of barbituric acid solution 
$0.5 \%$ (sample solution) was added. The absorbance of the solutions at $550 \mathrm{~nm}$ was determined using a UV-Visible Spectrometer (U-2900 Hitachi). The quantitative value of HMF was determined by using the proposed formula for the method [24,25].

\section{Diastase analysis}

To determine the diastasis number, 10 grams of honey was dissolved in $50 \mathrm{~mL}$ of distilled water in a beaker. After thawing, a 100 $\mathrm{mL}$ flask was transferred to the pellet and diluted with distilled water to the marker line. Then a series of 8 numbered test tubes, sequentially numbered from 1 to 8 , were placed in the distilled water and finally the starch + buffer mixture with $10 \mathrm{~mL}$ and a 1 $\mathrm{mL}$ pipette, respectively. The test tubes were mixed well. Then the pre-prepared $38-40{ }^{\circ} \mathrm{C}$ water bath was placed intact. The tubes were kept in the water bath for 1 hour. After one hour, the test tubes were removed from the water bath and cooled in cold water. 1 drop of $0.1 \mathrm{~N}$ iodine solution was added to each tube. The tubes were then mixed underneath. The tubes were examined from the first number 1 tube and the first tube was observed as the blue. The number of diastases corresponding to the previous test tube was read from the Table and accepted as the number of diastases of honey [24,25].

\section{Viscosity}

The viscosity measurements of the honey samples were performed at room temperature $24^{\circ} \mathrm{C}$ between the plates of a controlled shear rate rheometer (Physica MCR 302 Anton Paar, Germany). The upper plate (cone plate) was set at a distance of $0.101 \mathrm{~mm}$ before the onset of the reactions. Measurements were drawn in the shear rate range $10-100 \mathrm{~s}^{-1}$ at $293 \mathrm{~K}[24,25]$.

\section{Fracture index (Moisture determination)}

Determination of moisture in honey was performed with a refractometer. Honey samples were placed between the prisms of the refractometer using a spatula. The tool is closed according to the operating instructions. The temperature of the system was adjusted to $20^{\circ} \mathrm{C}$ and the optical refractive index of the honey was recorded $[24,25]$.

\section{Determination of pollen in honey samples}

Pollen analysis in honey samples was carried out by microscopical investigation [27]. Therefore, $10 \mathrm{~g}$ honey sample was weighed, and $10 \mathrm{~mL}$ of water was added to dissolve it completely. The resul- ting solution was poured into test tubes and centrifuged at 4500 rpm for $10 \mathrm{~min}$. The liquid fraction disintegrated in the centrifuge was poured into the slides with $1 \mathrm{~mL}$ pipettes. Pollen content of samples were observed under a microscope (Nikon Eclipse $\mathrm{Ci}, \mathrm{Ni}$ kon Instruments Inc., Tokyo, Japan).

Antioxidant activity of honey samples originated from seven different geographical regions of Turkey

Determination of the antioxidant capacity

The total antioxidant capacity of seven different honeys represented 7 geographical regions of Turkey was analyzed according to Erel's method [28]. Briefly, $100 \mathrm{mg}$ of honey sample was dissolved in $1 \mathrm{~mL}$ of distilled water. Five microliters of the sample was added to the wells and mixed with acetate buffer. Then, $15 \mu \mathrm{L}$ of ABTS+ reagent was added and the mixture was incubated at room temperature for 6 minutes. Then absorbance was measured at 734 nm using a Varioskan Flash Multimode Reader (Thermo Scientific). The reduction percentage was calculated in relation to the ascorbic acid equivalent concentration ( 0 - $1 \mathrm{mM}$ ). The antioxidant activities were expressed as mmol ascorbic acid equivalents per $100 \mathrm{~g}$ of honey. Radical scavenging activity (ABTS) as $\mathrm{mg} / \mathrm{mL}$ and the inhibition of ABTS in percentages were calculated. All experiments were performed in triplicates.

\section{Determination of total polyphenol content}

The total polyphenol content of the honey samples was determined spectrophotometrically by The Folin-Ciocalteu method [29]. Briefly, one gram of honey sample was dissolved in $10 \mathrm{~mL}$ of distilled water and filtered through filter paper. Fifty $\mu \mathrm{L}$ of honey sample and $250 \mu \mathrm{L}$ of Folin-Ciocalteu reagent were added to the wells of a 96-well plate in three replicates, and incubated for 5 minutes at room temperature. After adding $\mathrm{Na}_{2} \mathrm{CO}_{3}(7 \%, \mathrm{w} / \mathrm{v})$ solution and two hours incubation, the absorbance was read at $760 \mathrm{~nm}$ by Varioskan Flash Multimode Reader (Thermo Scientific, Waltham, MA). Gallic acid (0 - $500 \mathrm{mg} / \mathrm{L}$ ) was prepared for use as a reference standard. The polyphenol content was expressed as mg of gallic acid equivalents per $100 \mathrm{~g}$ (mg GA Eq/100 g) of the sample. All experiments were performed in triplicates.

\section{Determination of total flavonoid content}

The total flavonoid content of the honey samples was determined by using the aluminum nitrate colorimetric assay method [30]. 
Evaluation of Some Physico-chemical and Antioxidant Characteristics of Commercial Honey Samples Originated from Different Regions of Turkey

All samples were dissolved in tubes containing $80 \%$ of ethanol then $192 \mu \mathrm{L}$ of samples added to the wells. Then, $4 \mu \mathrm{L}$ of $1 \mathrm{M}$ potassium acetate and $4 \mu \mathrm{L}$ of $10 \%$ aluminum nitrate were added. Following the incubation for $40 \mathrm{~min}$ at room temperature, the absorbance of the reaction was measured at $415 \mathrm{~nm}$ by using a Varioskan Flash Multimode Reader (Thermo Scientific). Quercetin was used as the standard (0-500 mg/L). The results were expressed as milligrams of quercetin equivalents per $100 \mathrm{~g}$ (mg QEq/100 g) of honey. All experiments were performed in triplicates.

\section{Statistical analyzes}

Obtained data were analyzed using the Statistical Package for the Social Sciences version 21.0 (SPSS Inc, Chicago, IL, USA). The physico-chemical analysis of 30 honey samples were in duplicate whereas the antioxidant activity of 7 honey samples were examined in triplicate. All data were expressed as mean \pm SD of samples. Differences between samples were examined for statistical significance by Kruskal-Wallis test. A p value of $\leq 0.05$ was considered to be statistically significant.

\section{Results}

Physico-chemical analysis results of honeys

Physico-chemical properties of 30 extracted honey samples were analyzed, and the results were evaluated based on Turkish Food Codex [6] and European Commission Regulations [9]. Numerous studies have been presented the physico-chemical quality of honey samples from different regions of Turkey.

The amount of invert sugar in strained honey samples should be higher than $60 \%$. Invert sugar (glucose + fructose) amounts of 30 honey samples were found between $66.52-82.00 \%$ that means all the samples found appropriate to the Codex. The differences were statistically significant ( $p=0.002$ ). Sucrose composition (\%) of the honey samples was also acceptable according to the value of the Codex [6] and EU [9]. The significance level was 0.001. All samples except sample 14 are lower than the Codex limit value of $5 \%$. Moisture in percentages was determined by a refractometer and the results were collected in Table 1 . The differences were statistically significant $(\mathrm{p}=0.004)$. Highest acceptable value of Codex was shown with a line as $20 \%$ and all honey samples have a lower moisture amount than the limit. Free acidity values was found to be above $50 \mathrm{meq} / \mathrm{kg}$ which is the limit value in 2 honey samples and 28 other samples were found suitable (Table 1). Differences between honey samples were statistically significant $(p=0.001)$. Diastase number of the honey samples that indicates amylase enzyme activity. Eight samples were found below the limit value of Codex [6] and 22 samples were in the acceptable range. No significant differences were found statistically $(\mathrm{p}=0.097)$. Viscosity values were found between 6.41 - 58.53 Pa s (Table 1). According to pollen analysis, only one honey sample was found without pollen. By the microscopic analysis of the sample without pollen, starch particles were observed that should originated from artificially commercial glucose. Rest of the honey samples present rare, normal and abundant polen. The Turkish Food Codex [6] and The European Regulation [9] allow a maximum HMF content of $40 \mathrm{mg} / \mathrm{kg}$ honey. HMF amount of 3 samples were higher than $40 \mathrm{mg} / \mathrm{kg}$ which is the limit value of the regulations (Table 1). Differences were statistically significant $(\mathrm{p}=0.001)$. One of the samples with high HMF value was found to have commercial glucose, while the other 2 honey samples were thought to be exposed to a temperature well above $40{ }^{\circ} \mathrm{C}$. In the rest of the honey samples, HMF amount was between 0.77 - 38 .

\begin{tabular}{|l|c|c|c|c|c|c|c|}
\hline $\begin{array}{l}\text { Honey } \\
\text { samples } \\
(\mathbf{n = 3 0 )}\end{array}$ & Invert sugar (\%) & Sucrose (\%) & Moisture (\%) & $\begin{array}{c}\text { Free Acidity } \\
\text { (meq/kg) }\end{array}$ & $\begin{array}{c}\text { Diastase activity } \\
\text { (\%) }\end{array}$ & HMF (mg/kg) & $\begin{array}{c}\text { Viscosity } \\
\text { (Pa s) }\end{array}$ \\
\hline 1 & $74,63 \pm 0,8$ & $3,50 \pm 0,05$ & $19,40 \pm 0,28^{*}$ & $25,60 \pm 1,7$ & $10,9 \pm 2,8$ & $6,14 \pm 0,14$ & 13,72 \\
\hline 2 & $73,53 \pm 0,8$ & $0,10 \pm 0,48$ & $16,00 \pm 0,28$ & $33,41 \pm 0,9$ & $8,3 \pm 2,2$ & $3,46 \pm 0,11$ & 26,34 \\
\hline 3 & $70,42 \pm 0,5$ & $0,98 \pm 0,22$ & $16,60 \pm 0,14$ & $24,96 \pm 0,7$ & $8,3 \pm 2,2$ & $8,64 \pm 0,25$ & 9,04 \\
\hline 4 & $74,63 \pm 0,09$ & $1,13 \pm 0,54$ & $16,80 \pm 0,28$ & $17,92 \pm 0,85$ & $10.9 \pm 2,8$ & $2,88 \pm 0,12$ & 54,56 \\
\hline 5 & $69,44 \pm 0,4$ & $0,10 \pm 0,45$ & $14,60 \pm 0,28^{*}$ & $12,50 \pm 0,5$ & $13,9 \pm 3,5$ & $11,33 \pm 0,25$ & 35,38 \\
\hline 6 & $72,46 \pm 0,7$ & $3,02 \pm 0,09$ & $15,40 \pm 0,28$ & $12,50 \pm 0,4$ & $5,0 \pm 2,0$ & $2,30 \pm 0,10^{*}$ & 58,53 \\
\hline 7 & $74,63 \pm 0,25$ & 0,00 & $16,80 \pm 0,14$ & $25,00 \pm 1,1$ & 0 & $48,77 \pm 1,25^{*}$ & 13,78 \\
\hline 8 & $70,42 \pm 0,45$ & $3,47 \pm 0,1$ & $16,20 \pm 0,42$ & $12,50 \pm 0,8$ & $5,0 \pm 2,0$ & $24,77 \pm 1,12$ & 21,90 \\
\hline 9 & $60,52 \pm 0,75^{*}$ & $0,68 \pm 0,05$ & $15,80 \pm 0,14$ & $5,00 \pm 0,2^{*}$ & 0 & $43,97 \pm 1,42^{*}$ & 37,97 \\
\hline 10 & $76,92 \pm 0,92$ & $3,54 \pm 0,2$ & $18,00 \pm 028^{*}$ & $11,52 \pm 0,4$ & $17,9 \pm 4,5$ & $1,92 \pm 0,12^{*}$ & 17,72 \\
\hline
\end{tabular}


Evaluation of Some Physico-chemical and Antioxidant Characteristics of Commercial Honey Samples Originated from Different Regions of Turkey

\begin{tabular}{|c|c|c|c|c|c|c|c|}
\hline 11 & $66,60 \pm 0,45^{*}$ & $0,44 \pm 0,03$ & $17,00 \pm 0,28$ & $32,50 \pm 1,3$ & $10,9 \pm 2,8$ & $8,26 \pm 0,25$ & 18,60 \\
\hline 12 & $72,46 \pm 1,01$ & $4,24 \pm 0,15$ & $14,60 \pm 0,28^{*}$ & $17,50 \pm 0,7$ & $13,9 \pm 3,5$ & $10,18 \pm 0,41$ & 46,69 \\
\hline 13 & $72,99 \pm 0,75$ & $1,55 \pm 0,05$ & $16,20 \pm 0,42$ & $20,00 \pm 0,5$ & $6,5 \pm 1,7$ & $5,18 \pm 0,12$ & 15,14 \\
\hline 14 & $72,46 \pm 0,8$ & $5,37 \pm 0,05^{*}$ & $15,60 \pm 0,28$ & $11,26 \pm 0,3$ & $5,0 \pm 2,0$ & $8,83 \pm 0,15$ & 28,17 \\
\hline 15 & $72,46 \pm 0,45$ & $4,24 \pm 0,42$ & $16,20 \pm 0,28$ & $7,50 \pm 0,3^{*}$ & $17,9 \pm 4,5$ & $3,84 \pm 0,10$ & 17,69 \\
\hline 16 & $72,46 \pm 0,45$ & $4,25 \pm 0,22$ & $18,00 \pm 0,28$ & $20,00 \pm 0,8$ & $10,9 \pm 2,8$ & $3,07 \pm 0,05$ & 7,75 \\
\hline 17 & $79,37 \pm 0,5^{*}$ & $1,28 \pm 0,08$ & $16,60 \pm 0,28$ & $5,00 \pm 0,2^{*}$ & $8,3 \pm 2,2$ & $0,77 \pm 0,02^{*}$ & 14,99 \\
\hline 18 & $75,76 \pm 0,65$ & 0,00 & $17,20 \pm 0,28$ & $17,50 \pm 0,4$ & $13,9 \pm 3,5$ & $2,88 \pm 0,12$ & 13,61 \\
\hline 19 & $73,52 \pm 0,90$ & $0,44 \pm 0,01$ & $16,60 \pm 0,28$ & $22,50 \pm 1,1$ & $13,9 \pm 3,5$ & $3,84 \pm 0,14$ & 15,37 \\
\hline 20 & $69,44 \pm 0,55$ & $2,85 \pm 0,09$ & $16,40 \pm 0,14$ & $15,00 \pm 0,6$ & $10,9 \pm 2,8$ & $2,50 \pm 0,05$ & 12,94 \\
\hline 21 & $72,46 \pm 0,95$ & $1,04 \pm 0,04$ & $15,20 \pm 0,14$ & $20,00 \pm 0,8$ & $6,5 \pm 1,7$ & $16,13 \pm 0,8$ & 46,64 \\
\hline 22 & $72,46 \pm 0,95$ & $4,24 \pm 0,08$ & $16,60 \pm 0,42$ & $22,50 \pm 0,6$ & 0 & $61,82 \pm 1,5^{*}$ & 22,63 \\
\hline 23 & $62,27 \pm 0,35^{*}$ & $4,28 \pm 0,15$ & $14,60 \pm 0,28^{*}$ & $20,80 \pm 0,5$ & $17,90 \pm 4,5$ & $3,07 \pm 0,12$ & 54,19 \\
\hline 24 & $73,55 \pm 0,45$ & $2,19 \pm 0,05$ & $15,80 \pm 0,28$ & $65,50 \pm 1,5^{*}$ & $8,3 \pm 2,2$ & $4,03 \pm 0,14$ & 19,36 \\
\hline 25 & $71,47 \pm 0,27$ & $4,38 \pm 0,03$ & $16,20 \pm 0,14$ & $52,90 \pm 1,2^{*}$ & $13,9 \pm 3,5$ & $26,11 \pm 1,23$ & 17,29 \\
\hline 26 & $82,00 \pm 0,45^{*}$ & $1,24 \pm 0,05$ & $16,60 \pm 0,14$ & $22,50 \pm 0,8$ & $10,9 \pm 2,8$ & $34,56 \pm 1,41$ & 22,68 \\
\hline 27 & $76,45 \pm 0,7$ & $1,86 \pm 0,08$ & $15,40 \pm 0,28$ & $23,50 \pm 0,8$ & $13,9 \pm 3,5$ & $30,91 \pm 1,25$ & 23,82 \\
\hline 28 & $72,54 \pm 0,35$ & $3,25 \pm 0,05$ & $15,40 \pm 0,28$ & $19,00 \pm 0,5$ & $13,9 \pm 3,5$ & $38,21 \pm 1,65$ & 6,41 \\
\hline 29 & $70,45 \pm 0,4$ & $1,03 \pm 0,02$ & $15,40 \pm 0,28$ & $30,00 \pm 1,0$ & $10,9 \pm 2,8$ & $29,76 \pm 1,22$ & 22,83 \\
\hline 30 & $67,39 \pm 0,85$ & $0,94 \pm 0,03$ & $16,60 \pm 0,28$ & $25,00 \pm 0,7$ & $13,9 \pm 3,5$ & $37,82 \pm 1,81$ & 17,90 \\
\hline
\end{tabular}

Table 1: The results of physico-chemical characteristics of 30 honey samples are demonstrated.

* Mean values of samples are significantly different from each other $(\mathrm{p}<0.05)$.

Antioxidant capacity results of honeys

The total antioxidant capacity (TAC), total flavonoid content, total phenolic content and the radical scavenging activity (ABTS) of 
TAC values of $100 \mathrm{~g}$ honey samples ranged from $76 \pm 0.00$ to $100 \pm 0.01 \mathrm{mmol}$ Ascorbic Acid (A)Eq. The significant differences between honeys were found statistically $(p=0.005)$. Honey originated from Agean Region showed the highest value for TAC $100 \pm$ $0.01 \mathrm{mg} \mathrm{AEq} / 100 \mathrm{~g}$ significantly ( $\mathrm{p}=0.008$ ), whereas honey from Mediterranean Region showed the lowest value $76 \pm 0.00 \mathrm{AEq} / 100$ $\mathrm{g}$ (Table 2). Total phenolic content of honey from Agean Region was showed the highest value at $24.027 \pm 0.02 \mathrm{mg}$ Gallic Acid Eq/100 gr honey ( $\mathrm{p}=0.006)$, while its total flavonoid content was $71.850 \pm$ $0.03 \mathrm{mg}$ Quercetin Eq/100 g honey. On the other hand, the highest total flavonoid content was seen at $171.535 \pm 0.04 \mathrm{mg}$ Quercetin $\mathrm{Eq} / 100 \mathrm{~g}$ honey from Mediterranean Region ( $\mathrm{p}=0.006)$. Radical scavenging activity of honey from Aegean Region was $1.75 \pm 0.03$ $\mathrm{mg} / \mathrm{ml}$, while its inhibition rate of ABTS was calculated as $74.69 \%$ (Figure 2). The difference was statistically significant ( $p=0.005$ ).

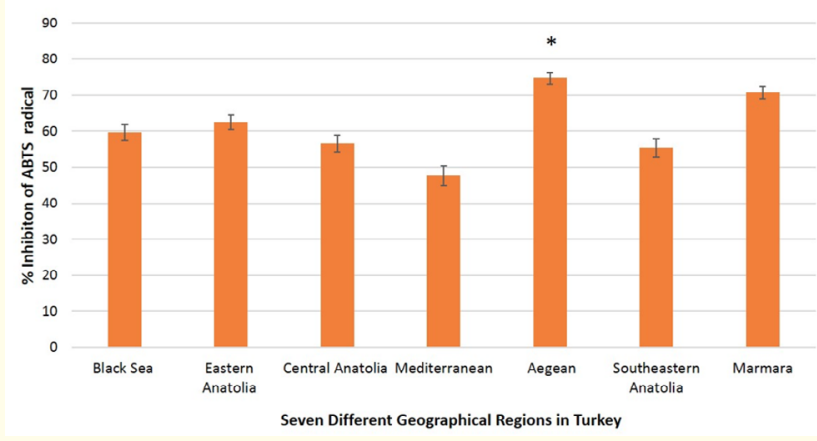

Figure 2: Inhibition of radical scavenging activity (ABTS) of 7 honeys from 7 different geographical regions of Turkey is given in percentages. * Differences are statistically significant when $\mathrm{p}$ $<0.05$.

\section{Discussion and Conclusion}

Considering the use of chemical formula drugs, their side effects on the body and the formation of resistance to drugs, it is inevitable to seek other alternatives such as natural products. About the subject, the use of so-called natural products of plant and animal origin for the treatment and prevention of various types of diseases is increasing [31]. Especially, honey as a natural bee product has attracted the attention of researchers to effectively combat these challenges of chemo drugs in recent years. Honey prevents the development of fungi and bacteria, especially against gram positive, and its antibacterial effect has been documented in many studies [32]. Honey may be beneficial for COVID-19 patients caused by the
SARS-CoV-2 virus by enhancing the host's immune system, improving comorbid conditions and antiviral activities [33]. It is known that there are honeys with features that go beyond the standards due to fraudulent or wrong practices such as heat treatment in markets and bazaars. In this study, it was found that 19 honey samples were suitable for the Codex in terms of the content of sucrose, invert sugar, moisture, and the number of diastases, HMF, commercial glucose and pollen analysis.

In our study, the amount of moisture of all samples was found in acceptable range. However, the amount of moisture of $4.29 \%$ honeys from Turkey was in an uncacceptable range [8]. In one study, the amount of moisture was reported between $17.00-19.40 \%$, while in another one, it was found between $14.70-23.00 \%$ [34]. Diastase was detected in 4 of the honey samples not suitable for the codex, free acidity in 2 samples, sucrose and diastase in 1 sample, diastase, HMF and commercial glucose in 1 sample and diastase commercial glucose and absence of pollen in 1 sample. In a study, the number of diastases showed $8.45-14.29$ while the amounts of HMF were found in the range of $10.50-36.02 \mathrm{mg} / \mathrm{kg}$ [34]. In another study, the amount of HMF was reported as 1.80 - $38.00 \mathrm{mg} / \mathrm{kg}$ [11]. Total glucose + fructose total was also investigated in honey samples reported to be between $53.67-59.61 \%$. Commercial glucose obtained by inverting starch was found in 2 samples. In this study, diastase activity of honeys were $0.0-22.4 \%$ whereas the activity of diastases was reported to be between 4.15 - $12.00 \%$ [11]. Sucrose values in honey samples varies between 0.0 and $5.37 \%$ in our study which are in the reported range according to another study [8]. It has been also reported that the amount of sucrose in Asian-Europen/Turkey group honeys is between 2.85 $8.44 \%$ [7]. In another study, sucrose amounts were found as 0.16 $-0.34 \%$ whereas that free acidity was found as $21.00-70.00$ meq/ $\mathrm{kg}$ [34]. In our study, the viscosity measurements at room temperature of 30 honey samples were ranged between 6.41 - 58.53 Pa s. Likewise, wide range in viscosity at $25^{\circ} \mathrm{C}$ was reported in Brazilian honeys 2.541 - 23.405 Pa s [35]. In contrast to these results, honey samples from Turkey showed viscosity at $25^{\circ} \mathrm{C}$ between $2.48-8.42$ Pa s [36]. In another work, the viscosity of rape honey collected from Lublin region in Polland varies at $20^{\circ} \mathrm{C}(33.6 \mathrm{~Pa}$ s) differed significantly ( $p \leq 0.01)$ with those at 30,40 and $50^{\circ} \mathrm{C}(8.2,2.5$, and 1.6 Pa s, respectively) [21]. In this point, the difference in viscosity results depends on the working temperature and the origin of honeys. When all results from physico-chemico analysis are taken into account, it has been summarized as while $63.33 \%$ of the extracted honey samples are found suitable and $36.7 \%$ are not appropriate to the Turkish Food Codex [6]. For this reason, our study showed 
that honeys offered for sale should be subject to more strict official control and inspection. In order to present the situation more clearly, there is a need for research and projects to be screened on a larger scale.

In numerous studies, it has been reported that honeys contain antioxidant agents such as carotenoid, ascorbic acid, tocopherol and polyphenols [36,37]. Therefore, we investigated the antioxidant activity of 7 honey samples presenting 7 geographical region of Turkey. Their total antioxidant capacity was found between 76 - $100 \mathrm{mmol} \mathrm{AE} / 100 \mathrm{~g}$ whereas phenolic content of honeys varies 4.72 - $24.027 \mathrm{mg}$ GA Eq/100 gr. The highest phenolic content showed the honey from Aegean Region, but the flavonoid content was the highest in honey from Mediterranean Region. In the same way, total phenolic content of honey samples originated from 4 different geographical regions of Turkey ranged from less to more Central Anatolia, South-East Anatolia, Aegean and Mediterranean [36].

In coclusion, the honey samples originated from different regions of Turkey showed more than half good quality. Their quality depends on various factors such as floral source, geographical origin, harvest seasons, packaging, process, and storage conditions. In general, honeys examined in this study showed high antioxidant capacity including phenolic and flavonoid contents. Thanks to wide and diverse flower resources of Turkey, the composition of honeys has high nutritional values.

\section{Contribution of Authors}

Conceptualization, M.G.B., A.G.B.; Investigation, M.G.B., B.Ö., Z.Ö., F.B.B., F.T., İ.K., N.K., T.S., T.S., N.Ö.; Visualization, A.G.B., M.G.B., Z.Ö., F.B.B.; Writing-original draft, M.G.B., A.G.B.; Writing-review and editing, M.G.B., A.G.B., B.Ö. All authors have read and agreed to the published version of the manuscript.

\section{Funding}

None.

\section{Acknowledgement}

The authors thank to Dr. Deniz Ceylan Tuncaboylu for viscosity measurments, and Dr. Ömer Uysal for statistical analysis.

\section{Conflicts of Interest}

The authors declare no conflicts of interest.

\section{Statement of Ethics}

This study was approved by the Bezmialem University Ethic Committee for Non- interventional Studies (No: 16/196 and date: 04.09.2018)

\section{Bibliography}

1. Ahmed S., et al. "Honey as a potential natural antioxidant medicine: an insight into its molecular mechanisms of action". Oxidative Medicine and Cellular Longevity (2018).

2. Hashem H., et al. "In silico approach of some selected honey constituents as SARS-CoV-2 main protease (COVID-19) inhibitors". Eurasian Journal of Medicıne and Oncology 4 (2020): 196-200.

3. Koussissis G., et al. "PAF antagonists in food: Isolation and identification of PAF antagonists in honey and wax". Revue francaise des corps gras 5.6 (1994): 127-132.

4. Ahmed A., et al. "Effect of natural honey on human platelets and blood coagulation proteins". Pakistan Journal of Pharmacutial Science 24 (2011): 389-397.

5. Turkish Statistical Institute.

6. Turkish Food Codex. Official gazette (2020).

7. Da Silva PM., et al. "Honey: Chemical composition, stability and authenticity". Food chemistry 196 (2016): 309-323.

8. Kahraman T., et al. "Physico-chemical properties in honey from different regions of Turkey". Food Chemistry 123 (2020): 41-44.

9. European Union Directive (EU). European Union Directive (2001).

10. White JW. "The Role of HMF and Diastase Assays in Honey Quality Evaluation" 75 (2015): 104-117.

11. Costa LSM., et al. "Determination of non-volatile compounds of different botanical origin Brazilian honeys". Food Chemistry 65.3 (1999): 347-352.

12. Terrab A., et al. "Characterisation of Spanish thyme honeys by their physicochemical characteristics and mineral contents". Food Chemistry 88.4 (2004): 537-542.

13. Bettar I., et al. "Characterisation of Moroccan Spurge (Euphorbia) honeys by their physicochemical characteristics, mineral contents and colour". Arabian Journal of Chemistry 12.8 (2019): 2052-2060.

14. Thrasyvoulou AT. "The Use of HMF and Diastase as Criteria of Quality of Greek Honey". Journal of Apicultural Research 25.3 (1986): 186-195.

15. Alvarez-Suarez JM., et al. "Antioxidant and antimicrobial capacity of several monofloral Cuban honeys and their correlation with color, polyphenol content and other chemical compounds". Food and Chemical Toxicology 48.8-9 (2010): 2490-2499. 
16. Fallico B., et al. "Effects of conditioning on HMF content in unifloral honeys". Food chemistry 85.2 (2004): 305-313.

17. Khalil MI., et al. "High 5-hydroxymethylfurfural concentrations are found in Malaysian honey samples stored for more than one year". Food and Chemical Toxicology 48.8-9 (2010): 23882392.

18. De Rodríguez G0., et al. "Characterization of honey produced in Venezuela”. Food Chemistry 84.4 (2004): 499-502.

19. Finola MS., et al. "Microbiological and chemical characterization of honeys from central Argentina". Food Chemistry 100.4 (2007): 1649-1653.

20. Küçük M., et al. "Biological activities and chemical composition of three honeys of different types from Anatolia". Food Chemistry 100.2 (2007): 526-534.

21. Kędzierska-Matysek M., et al. "Characterisation of viscosity, colour, 5-hydroxymethylfurfural content and diastase activity in raw rape honey (Brassica napus) at different temperatures". Journal of Food Science and Technology 53.4 2016): 2092-2098.

22. Moar N. "Pollen analysis of New Zealand honey". New Zealand Journal of Agricultural Research 28 (1985): 39-70.

23. Aytop Y., et al. "Consumers Behavior Towards Bee Products Consumption in The Centre District of Kahramanmaras Province". Kahramanmaraş Sutcu Imam University Journal of Agriculture and Nature 22 (2019): 449-455.

24. Turkish Standard Institute. TS 3036 Türk Standartları Enstitüsü, Ankara, Turkey (2010).

25. Association of Analytical Communities (AOAC). Official Methods of Analysis (21 ${ }^{\text {st }}$ Edition). Washington, DC: Association of Official Analytical Chemists (2019).

26. Turkish Standard Institute. TS 7780 Türk Standartları Enstitüsü, Ankara, Turkey (2018).

27. Jones GD., et al. "The use of ETOH for the dilution of honey". Grana 43.3 (2004): 174-182.

28. Erel 0. "Novel automated direct measurement method for total antioxidant capacity using a new generation, more stable ABTS radical cation" Clinical Biochemstry 37 (2004): 277-285.

29. Singleton VL., et al. "Analysis of total phenols and other oxidation substrates and antioxidants by means of folin-ciocalteu reagent". Methods Enzymology 299 (1999): 152-178.
30. Park YK., et al. "Comparison of the flavonoid aglycone contents of Apis mellifera propolis from various regions of Brazil". Archives of Biology and Technology (1997): 97-106.

31. Gunes Bayır A., et al. "Nutritional Assessment and Use of Complementary and Alternative Medicine in Cancer Patients Treated With Radiotherapy and Chemotherapy". Alternative Therapies in Health and Medicine 25.6 (2019): 28-33.

32. Mandal MD, and Mandal S. "Honey: its medicinal property and antibacterial activity". Asian Pacific Journal of Tropical Biomedicine 1.2 (2011): 154-160.

33. Lima WG., et al. "Bee products as a source of promising therapeutic and chemoprophylaxis strategies against COVID-19 (SARS-CoV-2)". Phytotherapy Research 35.2 (2021): 743-750.

34. Kambur M., et al. "Assesment of the Honey Samples Produced in Yığılca District of Düzce City by Using Chemical and Palynological Analysis". Uludag Journal of Beekeeping 15.2 (2016): 67-79.

35. Santos FK., et al. "Rheological and some physicochemical characteristics of selected floral honeys from plants of caatinga". Anais da Academia Brasileira de Ciências 86 (2014): 981-994.

36. Özcan MM and Ölmez Ç. "Some qualitative properties of different monofloral honeys". Food Chemistry 163 (2014): 212-218.

37. Machado AM., et al. "Honey Volatiles as a Fingerprint for Botanical Origin-A Review on their Occurrence on Monofloral Honeys". Molecules 25.2 (2020): 374.

\section{Assets from publication with us}

- Prompt Acknowledgement after receiving the article

- Thorough Double blinded peer review

- Rapid Publication

- Issue of Publication Certificate

- High visibility of your Published work

Website: www.actascientific.com/

Submit Article: www.actascientific.com/submission.php

Email us: editor@actascientific.com

Contact us: +919182824667 